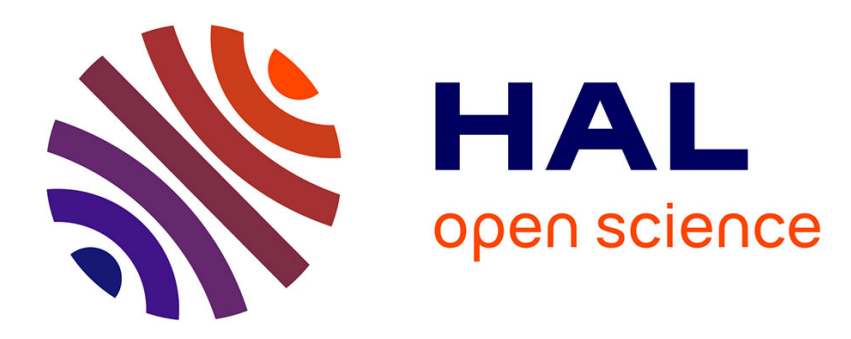

\title{
Knowledge governance within clusters: the case of small firms
}

Rachel Bocquet, Caroline Danièle Mothe

\section{To cite this version:}

Rachel Bocquet, Caroline Danièle Mothe. Knowledge governance within clusters: the case of small firms. Knowledge Management Research and Practice, 2010, 8, pp.229-239. 10.1057/kmrp.2010.14 . hal-00920052v2

\section{HAL Id: hal-00920052 \\ https://hal.science/hal-00920052v2}

Submitted on 13 Feb 2014

HAL is a multi-disciplinary open access archive for the deposit and dissemination of scientific research documents, whether they are published or not. The documents may come from teaching and research institutions in France or abroad, or from public or private research centers.
L'archive ouverte pluridisciplinaire HAL, est destinée au dépôt et à la diffusion de documents scientifiques de niveau recherche, publiés ou non, émanant des établissements d'enseignement et de recherche français ou étrangers, des laboratoires publics ou privés. 


\title{
Knowledge governance within clusters: The case of small firms
}

Rachel Bocquet, Caroline Danièle Mothe

\begin{abstract}
Despite the vast literature on knowledge management, little research has addressed the specificities of knowledge integration at the cluster level. Moreover, the cluster literature has not focused on the role that governance may play in knowledge management. This paper aims at bridging these two fields and filling this gap by analyzing the role of cluster governance in knowledge management. An empirical study of two small French firm clusters was carried out. These clusters are characterized by distinct knowledge management processes. In both cases, governance is necessary in order to support knowledge integration by member firms. Our results suggest that establishing an initial common knowledge base seems a prerequisite in order for the external knowledge identification and acquisition processes to take place. The activist role played by governance also seems more efficient than that of a broker. We discuss these results and their implications for policy-makers and cluster players.
\end{abstract}

Keywords: cluster, external knowledge integration, governance, proximity, small firms 


\section{Introduction}

In 2005, the French Government set up a new public policy for regional planning and development based on the creation of Competitiveness Clusters ("Pôles de compétitivité”). French Clusters are defined as the grouping of firms, research labs and education institutions established on a given territory and involved in a collaborative approach aimed at creating synergies around innovative collective projects oriented towards one or several given market(s). This definition emphasises the role played by geographical proximity, offering easier access to information, fostering knowledge exchange and facilitating the diffusion of innovations. However, a recent strand of literature shows that geographical proximity is not sufficient to facilitate knowledge creation and diffusion: "spillovers do not flow freely in the atmosphere. They can only be absorbed once communication protocols have been established" (Antonelli, 2006, p. 253). Thus, interactions organized at the cluster governance level may be necessary in order for firms to interact and for knowledge processes to occur. Accordingly, Steiner and Hartmann (2006) highlight "the importance of institutions that favour and support conscious effort in knowledge exchange” within clusters (ibid, p. 503) and advocate for more research on "the nature of institutions that would allow for greater emphasis on process creation and sharing" (ibid, p. 504).

Surprisingly, few empirical works have addressed the manner in which cluster governance supports knowledge processes and, more specifically, how this is achieved within clusters that are composed of Small and Medium-sized Enterprises (Cappellin, 2003). Along the same line, Bahlmann and Huysman (2008) recommend to identify the role of cluster governance with respect to knowledge. More generally, research on knowledge management in SMEs remains scarce (McAdam \& Reid, 2001; Liao et al., 2003; Davenport, 2005) even though such firms are critically short in new knowledge creation (Pillania, 2008). Our objective is to shed light on this issue, placing the emphasis on small firms as these are faced with specific obstacles that may prevent or hinder knowledge identification, acquisition and utilization (Thorpe et al., 2005; Pillania, 2008).

The paper is structured as follows. In the first section, we draw from the recent literature on proximity, moving beyond the geographical definition of space in economics, and provide a more dynamic framework inherited from the knowledgebased perspective (Grant, 1996; Brown \& Duguid, 1998; Nonaka \& Konno, 1998; 
Nonaka et al., 2006; Bahlmann \& Huysman, 2008; Kraaijenbrink \& Wijnhoven, 2008). In the second section, we clarify the role of governance in the integration of external knowledge within small firm clusters. In the third section, we present the empirical qualitative research methodology and the two cases on knowledge integration. In the last section, we discuss the main theoretical and managerial implications of our results, and propose some avenues for future research.

\section{Proximity and localized learning effects in small firm clusters}

A substantial body of research has confirmed that geographical proximity favours information access (Porter, 1990), and facilitates knowledge transfer and the diffusion of innovations (Jaffe et al, 1993; Feldman, 1999). Researchers often attribute these advantages to knowledge spillovers that cluster firms are able to access. Localized Knowledge Spillovers (LKS), "the direct and indirect transfer of knowledge from one party to another" (Gilbert et al., 2008, p. 405), are also viewed as “externalities bounded in space which allow companies that are established near important sources of knowledge to introduce innovations at a faster rate than rival firms located elsewhere” (Breschi \& Lessoni, 2001, p. 1). Despite the long established view that geographical proximity facilitates learning and innovation in clusters, a series of arguments, stemming from a recent strand of literature, questions these "purely" geographical effects.

For the "proximity view" (Boschma, 2005; Torre \& Rallet, 2005), geographical proximity per se is neither a necessary nor a sufficient condition for learning to take place, and different types of proximity are to be envisioned. Torre and Rallet (2005) distinguish geographical proximity, associated with pure agglomeration effects, and organized proximity, resulting in the ability for an organization (a firm, an administration, a social network, a community or an environment) to create common routines ("logic of belonging") and a shared set of representations or beliefs ("logic of similarity”) among its members. Boschma (2005) refines the concept of organized proximity into four different forms (cognitive, organizational, social, institutional). These authors share the view that geographical proximity is more a social effect of cluster members' embeddedness than an economic cause of agglomeration (Torre, 2008). As a consequence, geographical proximity alone cannot account for the localized 
learning that may take place between players because their interactions are strongly linked to cognitive, social, organizational and institutional dimensions.

Empirical studies tend to confirm these new approaches to proximity. In their study of three regional innovation networks in France, Torre and Rallet (2005) describe the difficulties encountered when creating networks from scratch, when these are not based on spontaneous organized links. They identify the obstacles that hinder transversal cooperation between heterogeneous local players (entrepreneurs, researchers, trainers, etc.) even when they are implanted on the same territory. Vale and Caldeira (2007), studying a localized footwear production system in Northern Portugal, emphasize the necessity of taking into account the "very nature" of spatial agglomeration, as composed of both close networks and distant networks. The authors observe a great difference between the two kinds of networks in terms of knowledge dissemination: local networks clearly aim at reducing production costs that limit the diffusion of new knowledge. On the contrary, distant networks seek to establish partnerships in strategic and value-added activities so as to access critical new knowledge. Results suggest that too much geographical proximity can hinder the learning ability of clusters members, especially in the case of small firms that lack the information and the human and financial resources necessary to target distant partners. The study also reveals that too much cognitive proximity between nearby firms (with similar bodies of knowledge) leads to a risk of cognitive lock-in and competence trap. In fact, firms become unable to perceive new opportunities and tend to unlearn habits or routines that have proved successful in the past (Boschma, 2005).

These obstacles to knowledge creation and diffusion are reinforced in the case of small firm clusters. Studies on small firms highlight that they often adopt individualistic behaviours to access scarce resources, such as labour, capital or services (Maskell \& Lorenzen, 2004). Their lack of managerial skill and cognitive resources limits their ability to perceive opportunities for collaboration (Hewitt-Dundas, 2006; Pillania, 2008). Moreover, they are unable to use external sources to generate new knowledge and innovation, even though these external resources are fundamental to them as they represent the greater part of their knowledge renewal (De Jong \& Marsili, 2006; Freel \& Harrison, 2006; Pillania, 2008). The wide diversity of members (private and public players) and of small firms themselves is another well-identified obstacle for knowledge creation and diffusion within industrial clusters (Alberti, 2001). As a consequence, knowledge in small firm clusters needs to be "governed". Governance is defined here as 
"the intended, collective actions of cluster players in view of upgrading a cluster" (Guilsing, 2000, p. 7). In that sense, governance appears to be as important as geographical proximity when knowledge diffusion and creation are at stake - possibly even more important (Alberti, 2001). In the same vein, studying the creation and categorization of knowledge management in automotive components SMEs in India, Pillania (2008, p. 1460) concluded that "government and industry associations play an important role in creating the eco-system for new knowledge creation among SMEs". Other works have shown that governance cannot be effective without a full understanding of the specific context (corporate strategies, industrial structures, profit cycles, state priorities etc.) in which the firms are embedded (Markussen, 1996). As Platt and Wilson (1999) point out, it is not merely a question of having the 'learning architecture' in place, but also of having the ability to use it - which varies across sociocultural contexts.

Although it is fundamental, the role of governance has been neglected in the literature focusing on cluster analysis, which rarely addresses governance implication in knowledge management, or how knowledge can be identified, acquired and utilized. Following the emergent knowledge-based view of clusters (Bahlmann and Huysman, 2008), we consider that governing knowledge in clusters requires a solid understanding of how governance can facilitate the integration of external knowledge at the interorganizational level (Grant, 1996; Kraaijenbrink \& Wijnhoven, 2008).

\section{External knowledge integration with governance in small firms' clusters}

The present research is anchored in a knowledge-based perspective that considers innovation as being based on new knowledge development and acquisition processes (Nonaka \& Takeuchi, 1995; Carbonara, 2004). From that perspective, a cluster is viewed as "a well-designed engine for information processing, but more importantly, it assiduously becomes a context in which knowledge - the engine's fuel - is created » (Nonaka et al., 2006, p. 1186). Due to various obstacles and to the complexity of the process itself, localized knowledge interactions between players cannot be considered to be spontaneous. The objective is to identify the way external knowledge flows can be integrated through actions taken by the governance. 
The main difficulty comes from the fact that clusters are composed of various organizations and individuals that can not be reduced to a focal organization. When moving from the intra- to the inter-organizational level, the question is not only to know how governance can help the players to manage knowledge heterogeneity within organizational boundaries (intra-organizational heterogeneity). Due to the external nature of knowledge, firms have to deal with two additional levels of knowledge heterogeneity, “extra-organizational” and “inter-organizational” (Kraaijenbrink and Wijnhoven, 2008). In that respect, the challenge for governance becomes twofold: Firstly, it must help firms find external knowledge and distinguish between relevant and irrelevant knowledge ("extra-organizational heterogeneity of knowledge”); and secondly, it should help these firms to bridge the differences (essentially of cognitive nature) between their organization and the sources of knowledge in order to make such knowledge usable (“inter-organizational heterogeneity of knowledge”). Considering these two levels of heterogeneity, Kraaijenbrink and Wijnhoven (2008) propose an external knowledge integration model based on three phases. In each of these phases, governance can play a specific role.

\section{The role of governance in the three external knowledge integration processes}

The first phase is knowledge identification, in which each firm distinguishes relevant external knowledge from irrelevant external knowledge. As previously mentioned, most small firms are unable to perceive and locate useful external knowledge despite the fact that it can improve their absorptive capacity (e.g. Cohen \& Levinthal, 1990; Zahra and George, 2002). Thus, governance can play a role of knowledge search aimed at capturing relevant external knowledge sources (Lazaric et al., 2008). This supposes that governance is able to identify cluster members' needs and expectations, and also to help firms manage knowledge heterogeneity. For Kraaijenbrink and Wijnhoven (2008), it is a question of balancing convergence (decreased heterogeneity)/divergence (increased heterogeneity). At the cluster level, this view can be seen as another way of interpreting the balance between local and global search, which depends on the specific context and/or type of cluster. Indeed, the creation of distant links tends to be a priority in traditional clusters (industrial districts), since these are composed of firms possessing a rather similar knowledge base operating on a local scale. By contrast, in the case of high technology clusters characterized by firms with diverse knowledge and external 
connections, the emphasis is placed on the creation of local interactions in order to reduce the cognitive distance between firms (Nooteboom, 2000).

The second phase is related to knowledge acquisition, which is the capacity to bridge differences between the firm's internal and external knowledge. This is an important phase since external knowledge is distributed among various decentralized units, embedded in individuals and organizations that differ on many aspects such as location, culture, language etc. Here, the role of governance is to facilitate knowledge dissemination and storage at the cluster level. Although ICT solutions are thought to be important to support this process (Nonaka \& Konno, 1998), non-ICT solutions are also essential for sharing and storing tacit knowledge, which is typically shared directly between individuals, either through conversation or direct observation (Dayasindhu, 2002).

The third phase is knowledge utilization. Firms have to make knowledge internally accessible and usable in order to apply it themselves or to prevent competitors from using it. Governance may also play a role in this third phase, providing levers to firms through collective and/or individual programs in order to encourage effective knowledge initiatives and utilization in individual firms (Pillania, 2008).

Following Jyrämä and Äyvärï (2007), governance is seen to play a mediator role that aims to permit the knowledge creation process at the cluster level. This role has been considered in various literatures. It is related to that of a "translator" or of a "broker" in the situated learning theory (Brown \& Duguid, 1998; Amin \& Cohendet, 2004), and to that of an "activist” in the knowledge management approach (Von Krogh et al., 1997; Nonaka et al., 2000). These distinctions are to be examined as the various roles that could be attributed to cluster governance may affect the learning processes itself.

\section{Cluster governance as a mediator}

In the learning situated theory, knowledge creation and diffusion takes place within communities of practice that enable their members to exchange information and knowledge (Brown \& Duguid, 1998; Torre, 2008). A community of practice is an active entity of knowing that reveals specific forms of knowledge through its daily practices. Such communities, bound by relations of common interest, purpose or passion, and held together by routines and varying degrees of mutualisation, are considered as key sites of knowledge creation, exchange and learning (Amin \& 
Cohendet, 2004). However, due to its social origin, knowledge does not flow easily between communities as far as practice is no longer shared. At the cluster level, governance can play a role of translator or of knowledge broker between different communities. The translator "can frame the interests of one community in terms of another community's perspective” (Brown \& Duguid, 1998, p. 36). He/she should possess special qualities and have a deep understanding of the different communities. $\mathrm{He} /$ she should also be able to secure the communities' trust. Most often, this will be an external mediator or a consultant. From its position in between communities the knowledge broker, would be able to match weak ties so that a player may have stronger ties with an outside community in order to develop "a shared understanding of what it does, or how to do it, and how it relates to other communities and their practices" (Brown \& Duguid, 1998, p. 32).

By contrast, the role of knowledge activist (Von Krogh et al., 1997) is to act as a bridge between individuals, organizations or communities, but also to act as a catalyst, to create spaces and occasion for joint actions (Jyrämä \& Äyvärï, 2007). The emphasis is placed on the creation of the ba (Nonaka \& Konno, 1998; Nonaka et al., 2000), a shared place for emerging learning interactions. Studying $R \& D$ collaborations between universities and firms, Brännback (2003) showed that the $B a$ is not merely a physical space, but also a mental space, a place for interaction facilitating absorptive capacity. More important, "without a $\mathrm{Ba}$, the common purpose is at risk of becoming merely supported or advocated intentions rather than true commitment” (Brännback, 2003, p. 5). In their study of the Sophia Antipolis high-tech cluster, specialized in Information and Communication Technologies and located in the south of France, Lazaric et al. (2008) illustrate how members' “potential” absorptive capacity (transformation phase) can turn into a "realized" absorptive capacity (emission phase). This transition is difficult and not automatic. The authors insist on the necessity for a specific coordination mechanism (in this case, a knowledge platform) that leads to the creation of a common space, thus allowing firms to position themselves within the cluster with respect to other member firms. This leads to the conclusion also proposed by Pillania (2008) that creating a common knowledge base is a prerequisite for the effective “awareness” and involvement of local capacities to take place.

Following Jyräma and Äyväri (2007), we consider that a Ba and communities of practices are both interesting concepts to look at governance as a mediator. For the situated learning theory, the emphasis is placed on "who" can bridge the different 
communities of practices. In the knowledge-based perspective, the question is "how" to foster learning process through the creation of shared representations and spaces.

\section{Research methodology and two cases of external knowledge integration}

We analyze two "competitiveness poles” (from here on, clusters), Arve-Industries and Imaginove, both composed mainly of SMEs located in the French Rhône-Alpes region. These two cases were selected because they share common characteristics (composed mainly of SMEs, located in the same region) but also because they differ significantly in terms of historical background (long tradition for Arve-Industries, short history for Imaginove), culture and leadership profiles (secrecy and tradition, openness and modern), type of industry (metal-working industry, cultural industry), position in the value chain (subcontractors, mainly for the automobile industry, and editors/distributors/producers), degree of heterogeneity and of competition among member firms (high competition between similar actors, low competition between heterogeneous).

After introducing the two cluster structures, we identify the external knowledge integration processes implemented by their respective governances. The research methodology is based on two case studies and 29 interviews conducted between January 2008 and February 2009 with governance players (see Appendix for more details). For Arve industries, all members of the executive committee were interviewed (7 persons) as well as 7 members of the Executive Board and the Administration Council and 5 project managers. For Imaginove, we conducted 10 interviews, with the director and all the members of the Board. This qualitative research was based on semistructured face-to-face interviews lasting two hours on average. All question items addressing the external knowledge integration phases (including the types of knowledge) were based on the empirical and theoretical literature (e.g., Nonaka, 1994; Lazaric et al., 2008; Martin-de-Castro et al., 2008). The interviews were transcribed and validated by the respondents. They were then coded according to the main themes identified in the literature: emergence of the cluster, features, governance structures and roles, external knowledge integration processes. Secondary data was also used for data triangulation: press extracts, government websites, articles and scientific communications at conferences, innovation and cluster observatories. A triangulation of 
primary and secondary data was performed in order to highlight the clusters characteristics and their operational functioning.

This methodology is unique and differs from previous studies which largely ignore mediators, i.e. governance players in our case. The large number of interviews conducted enabled us to limit the classical potential bias related to this type of method, based on players' perceptions and representations. It also presented the advantage of controlling whether the different governance players shared a common vision in terms of objectives and actions.

\section{CASE A: Arve-Industries}

Arve-Industries Haute-Savoie Mont-Blanc is composed (as of January 30, 2009) of 208 member companies (90\% SMEs), 28 public laboratories, 30 private laboratories, 12 technical training centres, 14 territorial actors and 13 municipalities. The companies are located in the Technic Valley industrial district, a territory with 800 SMEs involved in metal-working subcontracting. The Valley groups many businesses and skills: cutting, precision mechanics, assembly, materials surface treatment, precision grinding. The cluster was established at the initiative of politicians from the department of HauteSavoie in order to create a new dynamic for the old Technic Valley district. The cluster is in line with a pre-existing territorial logic (centred on the district) characterized by strong local roots, a legacy of private industry and initiatives, and a culture of secrecy. Everyone knows each other but there are different communities of practice that do not mix together. In such communities, the tacit nature of knowledge is facilitated by faceto-face contacts. Although the district has succeeded in pooling resources around a local platform, it is not surprising that it did not lead to bridge the different communities of practice. Subcontracting firms remain very specialized and have an interest in protecting their specific technical know-how. Hence, they can intentionally raise boundaries that prevent knowledge to flow to others, especially by secrecy. For the governance itself, confidentiality is an important dimension. Being a small sized cluster, it develops specialized research, and has to protect itself from imitators. At the cluster level, the governance admits that the risk of imitation is quite low. Governance acts in the area of overlapping communities of practices. This role is mainly orchestrated by local public institutions, which are key players within the governance (see Appendix 1). All governance members come from the former industrial district. 
The cluster, through its governance, insists on the role played in the identification of external knowledge, as screening and technological watch is essential for the future of the mechatronics activity (based on the integration of mechanics, electronics and computing). However, a distinction has to be made between the “average” SMEs and the cluster “engines”, which are able to perceive opportunities and benefits from external knowledge. As such, these "leading firms" have already built their own networks, often distant and international. For them, the cluster plays a screening role and can lead to new connections through the Technical Center for Cutting and Mechatronics (CTDEC), the innovation centre (Thésame) or the University. Until now, the cluster governance has privileged the identification of technological knowledge to respond to new customer requirements. However, essential technological knowledge is not sufficient to counteract low cost competitors and to lessen the high dependence towards some automobile constructors or equipment manufacturers. Aware of these challenges, the governance seeks to broaden the firms' external knowledge spectrum by identifying relevant organizational and managerial knowledge for subcontracting SMEs. But, as mentioned by governance members, SMEs are not in this perspective mainly because short-term imperatives still prevail.

For the acquisition and utilization of external knowledge, the governance of Arve Industries encourages collective innovation projects through various programmes in industrial performance, cutting, collaborative innovation, quality, etc. Once again, we observe that these programmes are confined to the "engines". The efficiency of such actions is somehow limited by the low motivation of a large number of member firms. The governance is also active in setting up other types of schemes (collective and individual actions and training) designed to facilitate knowledge acquisition and utilization. Yet, for most firms, the main lever is essentially financial in nature, and quite artificial since there is no shared cognitive orientation.

The governance of Arve-Industries acts as a knowledge broker between different communities of practice at the cluster level. For most governance members, their implication in the cluster is an additional task to their existing jobs. Each of them is directly involved in programme leadership (training and consulting, collective actions, R\&D collaborations, etc.) and endeavours to build ties between the different communities. Aware of the lack of involvement of small members, the governance is giving a new direction to the programs through a more institutionalized structure. One of the main changes consists in relying more on external competencies to manage 
knowledge in the various programmes. The objective is to shift from a status of “amateurs" whose competencies are not primarily in knowledge management to that of “experts” capable of "managing open systems interacting with their environment". Clearly, the question here is about "who” should manage knowledge creation.

\section{Case B: Imaginove}

Imaginove is composed (as of January 30, 2009) of two associations and, indirectly, of more than 200 firms (97\% of SMEs) in the cultural industries, 7 research laboratories and 4 training centres. Imaginove was created by three founders: Lyon Game, Image Rhône-Alpes and CITIA (see Appendix 1 for more details on these institutions). Their members operate in the video game, multimedia, audiovisual and image industries. The cluster is in line with a regional policy implemented in 2002 by the Rhône-Alpes region around a Digital Entertainment cluster and initially focused on video games. In July 2005, the regional cluster, named Imaginove, was labelled “competitiveness pole” and opened up to the image industry, following the motivation of the Region to create synergies between these industries. Today, Imaginove is both a regional cluster and a national “competitiveness pole”.

Imaginove is concerned with creative (excluding architecture, etc) and digital "content industries". There is no hardware, no cabling. Therefore, no major firm is involved. Member firms are small: even Atari and Ubisoft are small as their headquarters are established outside of the region. The main objective of the governance is to take into account the specificities of these small firms that lack strategic vision in order to make them work together. Players from the three industries (animation, video games and film production) get to know each other and initiate interactions. This was facilitated by the fact that the three founders are active in web communities and in the pre-existing professional associations. Coordination is ensured by a permanent team composed of 5 employees who do not belong to the three associated industries. Cooperation between firms is mainly driven by this team (see Appendix 1 for more details on the governance).

Governance team members are actively involved in the identification phase. They help firms to locate relevant external knowledge. The governance is very active, especially with regards to prospective, strategic screening (from the National Communication Council, the Region, the "Grand Lyon", for calls for projects, etc.), and relations with the institutional partners that provide funding and potential development. 
The cluster sees itself as a provider of "general” knowledge to member firms. This type of knowledge is seen as an essential base to support firms' growth - which is a priority for the cluster. There are few needs oriented towards new scientific or technological knowledge, except for the video game industry. The animation sector does not need such knowledge, and the multimedia sector uses standard technical knowledge. Most firms are mainly interested in commercial and managerial knowledge (project management, production organization, etc.). The governance thus responds to their immediate short-term concerns.

The acquisition phase aims at articulating existing knowledge, at developing links between the three industries, also at expanding the knowledge base beyond the region. Imaginove creates relations between competences, spaces for transferring general knowledge, and identifies business gateways. Through various programmes and tools, it provides incentives for member firms to enhance their capacity of projecting themselves in a longer term (2-year horizon). For instance, planning and holding of events is essential for members. The city of Lyon is known for its video game industry, Annecy for animation. SMEs expect the governance to be very active in the organization of such events, which are particularly important for the image of the entire industry. This also creates new opportunities for firms to meet each other in a transversal logic (crossindustries approach). Another example concerns the creation of a collaborative platform where the firms' different competencies are precisely detailed and are available for consultation by all cluster members. However, firms do not have the same level of awareness within the cluster:

Although Imaginove governance faces similar problems as Arve-Industries, related to members' awareness and implication, it seems that it is better able to take into account their specificities, especially those linked to their activity. Firms operating in the audiovisual industry are interested in lobbying and financial subsidies. In the videogame industry, firms do not need help, they mainly do things on their own but they do have an interest in commercial development and promotion (reputation of the Region). The animation sector lies somewhere between the two, with an interest in the international positioning of the industry. Imaginove is less involved in the utilization phase, essentially because of a lack of resources. The focus is clearly on creating the “foundations", the prerequisites that will encourage member firms' awareness and their involvement in collaborative projects. 
Imaginove acts more as an activist in enabling conditions and contexts for knowledge creation. The focus for the governance is on fostering learning preconditions through the creation of different spaces where members may interact in a transversal logic. Training and consulting, collective actions, follow-up meetings and project labelling are carried out by experts and consultants who are external to the governance. In this case, contrary to Arve-Industries, we observe a clear-cut distinction between the role of the Administration Council, which provides the major strategic orientations, and the "operational governance" (team of 5 employees plus the director), which creates the various actions related to employment and training, innovation and R\&D, commercial and international, fairs and events, and communication.

\section{Discussion}

The aim of our research was to fill a gap in the literature on knowledge management in SME clusters. Considering the increased attention paid to these aspects in our knowledge economies and the place of small firms in economic activities, understanding how cluster governance encourages knowledge dissemination and creation is essential. In both cases, geographical proximity is not sufficient to facilitate knowledge transfers among nearby firms, and "something else" is at play.

In Arve-Industries, close cognitive proximity between firms engaged in a same industrial activity entailed major obstacles to knowledge management and learning. Within Imaginove, the greater cognitive distance between members prevented them from immediately perceiving the potential advantages of co-localization. Consistent with the findings of Vale and Caldeira (2007), geographical proximity matches better with a "certain" degree of cognitive distance between members, thus corroborating the role governance can play in finding the "right" cognitive distance. In the case of ArveIndustries, the high cognitive proximity is detrimental to external knowledge integration - regardless of the phase considered. The governance thus endeavours to secure access to heterogeneous sources of information and to offer an opening onto the external world (Boschma, 2005), but with limited success. By opposition, Imaginove focuses on establishing local links so as to reduce the cognitive distance between firms belonging to different industries. Our study reveals that, after three years of existence, thanks to its activist role the governance of Imaginove has succeeded in creating a $B a$ (Nonaka \& 
Konno, 1998; Nonaka et al., 2000; Brännback, 2003), a context shared between the three industries.

These considerations lead to our major result, which is related to the different roles governance should play in each of the three main knowledge management phases. We have seen that in phases 1 and 2 (identification and acquisition), cluster governance plays a direct role in preparing the appropriate conditions and the right context for firms to identify and acquire knowledge. Through adapted formal and informal mechanisms and tools, the governance is able to identify the "right" external knowledge for member firms and to bridge knowledge between them. This is especially essential in clusters where member firms are small and are not often in a position where they can proceed to this identification on their own.

The governance of Imaginove is essentially focused on enhancing the awareness of its member firms and on reducing the high cognitive gap. It is also able to respond aptly to the specific needs of its members in terms of identification and acquisition of general knowledge, through organizing events for example. Instead, the governance of Arve-Industries seems more ambitious with respect to technological knowledge acquisition and utilization, but with the risk of neglecting firms that are not able to perceive the knowledge and innovation opportunities. This is where Arve-Industries has failed: by not paying attention to the initial phases of the knowledge management process, in believing that shared representations and collective knowledge were preexistent to the cluster, through the long-lasting district tradition in particular.

In Arve-Industries, the governance is highly active, and is an integral part of the various supporting schemes. This knowledge broker (Brown \& Duguid, 1998; Amin \& Cohendet, 2004) coordination system, assumed by institutional members, appears to be "natural" in this traditional and historic context. However, it is closer to the "scaledown” (Pillania, 2008) version of practices that can be observed for knowledge management within large firms. The governance did not create a collective vision around the major industrial stakes with regards to the acquisition of new competences in mechatronics. Arve-Industries has focused on new knowledge creation, thus on output phases. However, the objective of creating new knowledge has not yet been achieved. Thus, it is not surprising that only the engines play an active part in projects and actions.

This broker role supporting external knowledge integration differs radically from the activist role (Von Krogh et al., 1997) played by Imaginove, where there is no nesting between those who organize and those who do. Within Imaginove, the 
governance insisted on the preliminary phase of creating common knowledge concerning the necessity of convergence towards cross-media activities, before then moving on slowly and progressively through the various phases. It emphasized input phases, focusing on knowledge identification and acquisition. It seeks to increase information related to competencies and cooperation opportunities. The objective is to encourage firms to cooperate by creating shared representations and a common resource base. Competence codification creates a common basis that improves transfer and cooperation opportunities at the local and non-local levels.

Our results emphasize the fact that for both identification and acquisition phases, both brokers and activists could be adapted; however, the activist role of Imaginove outperforms the broker role of Arve-Industries (as it has succeeded in creating the enabling conditions and collective representations). For phase 3 (utilization), the governance plays a lesser role. However, a broker role is clearly not adapted to this phase as governance should coordinate competencies in order to favour firms' absorption (through financing external consultants for instance). Due to the very different nature of the governance members in both clusters, we also note that they have a different representation of their own involvement in the cluster and placed the emphasis on different types of knowledge. In Arve-Industries, governance members belong, except for the Economic Development Agency, to scientific and technological institutions. Acting as a knowledge broker, it is no surprise that technological knowledge is put forth. The risk is that geographic proximity could act as a way to legitimate the action of the various governance institutions. On the contrary, members of the Imaginove governance have been keen to translate the needs of cluster member firms and to offer them well-adapted services. Through its activist role Imaginove seeks to create a shared context between three distinct industries. In our research, the activist role seems to be more adapted to the specific context of SMEs clusters.

\section{Conclusion, limitations and future research}

The proximity view defines a turning point in the study of knowledge creation and diffusion within clusters. Geographical proximity between innovative firms is no longer a sufficient condition in order to ensure that knowledge processes will occur. In the case of small firm clusters, this approach provides support in favour of the role governance should play in organizing efficient local interactions between players. Yet, 
at the same time, little is said about "who" and "how" to manage knowledge processes. The external knowledge integration approach (Grant, 1996; Kraaijenbrink \& Wijnhoven, 2008) allows us to fill the gap by distinguishing different phases in the knowledge process and the associated mediator roles.

An empirical study was undertaken to investigate the role of governance in knowledge management in two small firm clusters. Even though they largely differed in structural characteristics, they both faced the same problem of lack of involvement of their smaller members. Our study shows that the two governances propose different solutions but are still far from offering the ideal process described in the knowledgebased literature. One form of governance (Imaginove) seems to outperform the other (Arve-Industries) as it focuses on the identification and acquisition of external knowledge. This input knowledge management strategy appears to be adapted to the short-term needs of its members and participates in the creation of a common knowledge base. In line with Jyräma and Äyväri (2007), we also show that the activist role (Imaginove) is more effective than the broker role (Arve-Industries). It would be interesting to verify whether this advantage persists over time.

Indeed, the major limitation of the present study is its static nature. Future research could study the effects of cluster lifecycle on knowledge management through longitudinal studies as the constraints and performance factors may differ (Bresnahan et al., 2001). Also, linking cluster lifecycle to industry lifecycle could provide interesting insights to study their moderating influence on the relationship between geographic proximity and firm innovation, thus expanding existing research in the field (e.g. Audretsch \& Feldman 1996; Davenport, 2005). Knowledge management may depend on the phase in the industrylife cycle, which is rather different in our two cases: mature for Arve-Industries, emerging as far as cross-media is concerned within Imaginove. In this respect, our preliminary results reveal differences, especially concerning the type of external knowledge. However, our study did not enable us to specifically study the impact of the type of industry, thus arguing for further research on the comparison of different activities.

Our results have far-reaching managerial implications, not only for firms engaged in cluster activities, but also for institutional cluster governance players and policy makers. We have identified two radically different modes of cluster governance, of integrating external knowledge, and of managing the knowledge management phases - and their preconditions, i.e. member firms' common knowledge base and shared 
representations. Imaginove is close to the coordination system found in clusters 'à la Porter' as is the case in the Silicon Valley. The roles of translation and coupling are played by private actors who act as consultants (the capital-riskers and business angels in the case of the Silicon Valley). Arve-Industries can be assimilated to a "territorial” or “institutional” governance mode (Gilly and Wallet, 2001) as all governance players are individuals employed by local public institutions.

As cluster governance is keen to enhance members' competitiveness and innovation performance, firms should become more aware of the advantages of belonging to a cluster. In the first place, governance should create common representations based on the specific industrial knowledge base. If firms are too close (geographically or in terms of activity) the main tasks should be to promote the advantages of co-opetition on one hand, and of developing outbound networks on the other hand: « improving cooperative relationships and building a network that reaches outside of the region may prove more productive for some localities than concentrating on indigenous firms” (Markusen, 2006, p. 27). In the opposite case, when firms are distant, reinforcing links within the cluster is a prerequisite for further governance actions. Cluster competitiveness does not rely on the aggregation of knowledge from individual firms, but rather on its re-combination through efficient interactions. The role of governance is then essential for creating and sustaining such interactions, especially in the case of small firms that are not able to perceive and/or capture strategic opportunities.

Evidently, closely-related problem of firms’ absorptive capacity, largely studied in the literature since Cohen and Levinthal's (1990) landmark article, cannot be ignored, as all governance efforts will remain vain for cluster members who lack absorptive capacity. This aspect has remained largely ignored as far as small firms are concerned. We hope future research will investigate further the analysis of knowledge management in clusters, as these organizational forms, based on different types of proximity, are in constant development in our knowledge-based economies.

\section{References}

Alberti F (2001) The Governance of Industrial Districts: a Theoretical Footing Proposal. Liuc Papers 82, Serie Piccola e Media Impresa 5.

Amin A and Cohendet P (2004) Architectures of Knowledge: firms, capabilities, and communities. Oxford University Press, New York. 
Antonelli C (2006) The Business Governance of Localized Knowledge: An Information Economics Approach for the Economics of Knowledge. Industry and Innovation 13(3), 227-261.

Asheim B and Gertler M (2005) The Geography of Innovation: Regional Innovation System. In The Oxford Handbook of Innovation, Fagerberg J, Mowery D and Nelson R (eds), Oxford University Press, New York, 291-317.

Audretsch DB and Feldman M (1996) R\&D spillovers and the geography of innovation and production. American Economic Review 86, 630-640.

Bahlmann MD and Huysman MH (2008) The emergence of a knowledge-based view of clusters and its implications for cluster governance. The Information Society 24, 204-318.

Boschma RA (2005) Proximity and innovation: a critical assessment. Regional Studies 39, 6174.

Brännback M (2003) R\&D collaboration: role of $\mathrm{Ba}$ in knowledge-creating networks. Knowledge Management Research \& Practice. 00, 1-11

Breschi S and Lissoni F (2001) Knowledge spillovers and local innovation systems: a critical survey. Industrial and Corporate Change 10(4), 975-1005.

Bresnahan T, Gambardella A and Saxenian A (2001) Old Economy Inputs for New Economy Outputs: Cluster Formation in the New Silicon Valleys. Industrial and Corporate Change 10(4), 835-860.

Brown JS and Duguid P (1998) Organizing knowledge. California Management Review 40(3), 90-111.

Cappellin R (2003) Territorial knowledge management: toward a metrics of the cognitive dimension of agglomeration economics. International Journal of Technology Management 26 (2/3/4), 303-325.

Carbonara N (2004) Innovation processes within geographical clusters: a cognitive approach. Technovation 24, 17-28.

Cohen WM and Levinthal DA (1990) Absorptive Capacity: A New Perspective on Learning and Innovation. Administrative Science Quarterly 35, 128-152.

Dayasindhu N (2002) Embeddedness, knowledge transfer, industry clusters and global competitiveness: a case study of the Indian software industry, Technovation. 22, 551-560.

Davenport S (2005) Exploring the role of proximity in SME knowledge-acquisition. Research Policy 34, 683-701.

De Jong JP and Marsili O (2006) The fruit flies of innovation: A taxonomy of innovative small firms, Research Policy 35, 213-229.

Feldman M (1999) The new economics of innovation, spillovers and agglomeration : a review of empirical studies. Economics of Innovation and New Technology 8, 5-25. 
Freel MS and Harrison RT (2006) Innovation and cooperation in the Small firm sector: Evidence from 'Northern Britain', Regional Studies, 40(4), 289-305.

Gilbert BA, McDougall PP and Audretsch DB (2008) Clusters, knowledge spillovers and new venture performance: An empirical examination. Journal of Business Venturing 23, 405422.

Gilly JP and Wallet F (2001) Forms of proximity, Local Governance and the Dynamics of Local Economic Spaces : The case of Industrial Conversion Processes, International Journal of Urban and Regional Research, 25(3), 553-570.

Guilsing V (2000) Cluster Governance. How clusters can adapt and renew over time. DRUID PhD-conference, January, Copenhagen, Danemark.

Grant R (1996) Prospering in dynamically-competitive environments: organizational capability as knowledge integration, Organization Science 7(4), 375-387

Hewitt-Dundas N (2006) Resources and capabilities constraints in small and large plants. Small Business Economics 26, 257-277.

Jaffe AB, Trajtenberg M and Henderson R (1993) Geographic localization ok knowledge spillovers as evidenced by patent citations. Quarterly Journal of Economics 63, 577-598.

Jyrämä A and Äyväri A (2007) Fostering learning - the role of mediators. Knowledge Management Research \& Practice 5, 117-125.

Kraaijenbrink J and Wijnhoven F (2008) Managing heterogeneous knowledge: a theory of external knowledge integration, Knowledge Management Research \& Practice 6, 274286.

Lazaric N, Longhi C and Thomas C (2008) Gatekeepers of knowledge versus platforms of knowledge: from potential to realized absorptive capacity. Regional Studies 42(6), 837852.

Liao J, Welsch H and Stoica M (2003) Organisational absorptive capacity and responsiveness: an empirical investigation of growth-oriented SMEs. Entrepreneurship Theory and Practice 28, 63-86.

Markusen A (1996) Sticky places in slippery space: a typology of industrial districts, Economic Geography 72(3), 293-313.

Martin-de-Castro G, Lopez-Saez P and Navas-Lopez JE (2008) Processes of knowledge creation in knowledge-intensive firms : Empirical evidence from Boston’s Route 128 and Spain. Technovation 28, 222-230.

Maskell P and Lorenzen M (2004) The Cluster as Market Organization. Urban Studies 41(5/6), 991-1009.

McAdam R and Reid R (2001) SME and large organization perceptions of knowledge management: comparisons and contrasts. Journal of Knowledge Management 5, 231241. 
Nonaka I (1991) The knowledge-creating company. Harvard Business Review 69, 95-105.

Nonaka I (1994) A Dynamic Theory of Organizational Knowledge Creation. Organization Science 5(1), 14-37.

Nonaka I and Konno N (1998) The concept of 'Ba': building a foundation for knowledge creation. California Management Review 40(3), 40-54.

Nonaka I, Toyama R and Konno N (2000) SECI, Ba and leadership: a unified model of dynamic knowledge creation. Long Range Planning 33(1), 5-34.

Nonaka I, Von Krogh G and Voelpel S (2006) Organizational knowledge creation theory, Evolutionary paths and future advances. Organization Studies 27(8), 1179-1208.

Nonaka I and Takeuchi H (1995) The Knowledge-Creating Company. Oxford University Press, New York.

Nooteboom B (2000) Learning by interaction: absorptive capacity, cognitive distance and governance. Journal of Management and Governance. 4, 69-92.

Pillania R (2008) Creation and categorization of knowledge in automotive components SMEs in India. Management Decision 46(10), 1452-1463.

Sammarra A and Biggiero L (2008) Heterogeneity and Specificity of Inter-Firm Knowledge Flows in Innovation Networks. Journal of Management Studies 45(4), 800-829.

Steiner M and Hartmann C (2006) Organizational Learning in Clusters: A Case Study on Material and Immaterial Dimensions of Cooperation. Regional Studies 40(5), 493-506.

Thorpe R, Holt R, Macpherson A and Pittaway L (2005) Using knowledge within small and medium-sized firms: a systematic review of the evidence. International Journal of Management Reviews 7(4), 257-281.

Torre A (2008) On the role played by temporary geographical proximity in knowledge transfer. Regional Studies 42(6), 869 - 889.

Torre A and Rallet A (2005) Proximity and Localization. Regional Studies 39(1), 47-59.

Vale M and Caldeira J (2007) Proximity and Knowledge governance in Localized Production systems: the footwear industry in the north region of Portugal. European Planning Studies 15(4), 531-548.

Von Krogh G, Nonaka I and Ichijo K (1997) Develop knowledge activists, European Management Journal 5(5), 475-83.

Zahra S and George G (2002) Absorptive capacity: A review, reconceptualization, and extension. Academy of Management Review 27(2), 185-203. 


\section{Appendix : Description of the two governance structures}

Arve-Industries is headed by a President who is the leader of a local SME and has a high degree of legitimacy vis-à-vis cluster members. The governance is composed of:

- A strategic governance. The Board of Administration includes 60 members who meet twice a year. The Executive Board, appointed by the General Assembly, is responsible for developing the strategy and the main objectives. It is composed of 17 members who meet every 2 to 3 months;

- An operational governance. The Steering Committee is composed of 7 members who meet every 2 weeks. It manages the cluster via transverse processes: economic intelligence, new project labeling, marketing of innovations, strategic leadership. It is also in charge of the evaluation of projects, their reporting, external relations and the daily operations.

At Arve-Industries, local public institutions are significantly involved in the governance as internal stakeholders: University of Savoie, Economic Development Agency, Thésame (Innovation center) and CTDEC (Technical Center for Cutting and Mechatronics). They are also present on the Steering Committee, which represents the main body in charge of cluster operations (and strategic orientations). Local public institutions, thus, have a strong and direct involvement in both the strategic and operational governance.

By contrast, Imaginove is headed by a director, appointed by the Board, who is dedicated to the cluster on a full-time basis. The governance (until March 2009) is composed of:

- A strategic governance. The Board consists in 9 persons from the three founding institutions (3 persons from Lyon Game, 3 from Images Rhône Alpes and 3 from CITIA). Lyon Game is a professional association for video game firms, Images Rhône Alpes is the equivalent for firms in the image industry, and CITIA in the animation industry). The Board meets once a month, and gives the strategic orientations, defines the objectives and the cluster collective actions;

- An operational governance. The permanent team, consisting of the Director and 4 persons in charge of innovation, international and commercial activities, events and employment and training, ensures project implementation and monitoring and cluster animation. The involvement of public institutions in the governance, whether local (the "Grand Lyon"), departmental (the “General Councils”), regional (the Rhône-Alpes region) or national (the State through its Regional Direction for Industry, Research and Environment) is low. These institutions are invited to participate to some of the Board meetings in which they will act as external stakeholders.

This governance model contrasts with that of Arve-Industries, with a full dedicated team and weak public institutions' involvement (and the involvement of regional, not local, institutions) and with private actors playing a key role. 